\title{
Knowledge, Attitude, and Practice Towards COVID-19 Among Pharmacists: A Cross-Sectional Study
}

\author{
Maha M AIRasheed (D) \\ Amani H AIShahrani' \\ Sara A AIMuhaini (D) \\ Hadeel A AlKofide (D) ${ }^{\prime}$ \\ Tariq M Alhawassi ${ }^{1,2}$ \\ Ahmed Aldemerdash (ID) \\ Omar A Alhaj (D) ${ }^{3}$ \\ Nicola L Bragazzi ${ }^{4}$ \\ Haitham A Jahrami iD 5,6 \\ 'Department of Clinical Pharmacy, \\ College of Pharmacy, King Saud \\ University, Riyadh, Saudi Arabia; \\ ${ }^{2}$ Medication Safety Research Chair, \\ College of Pharmacy, King Saud \\ University, Riyadh, Saudi Arabia; \\ ${ }^{3}$ Department of Nutrition, Faculty of \\ Pharmacy and Medical Sciences, \\ University of Petra, Amman, Jordan; \\ ${ }^{4}$ Laboratory for Industrial and Applied \\ Mathematics, Departments and Statistics, \\ York University, Toronto, ON, Canada; \\ ${ }^{5}$ Ministry of Health, Manama, Bahrain; \\ ${ }^{6}$ College of Medicine and Medical \\ Sciences, Arabian Gulf University, \\ Manama, Bahrain
}

Purpose: The COVID-19 outbreak has caused governments to put pandemic-related guidelines requiring compliance and understanding by healthcare professionals to mitigate its spread uncontrollably. We studied pharmacists' knowledge, attitude, and practice towards the COVD19 outbreak compared with other healthcare workers during the pandemic in Saudi Arabia.

Methods: We surveyed pharmacists' socio-demographics $(n=50)$ compared with other healthcare professionals $(n=378)$ during lockdown starting in June 2020. We measured respondents' level of knowledge ( $n=10$ questions, maximum score of 10$)$, attitude $(n=17$ questions, maximum score of 80 ), and their practices ( $n=16$ questions, maximum score of 80 ) towards COVID-19 infection.

Results: Median knowledge score was 8 (25th-75th percentiles: 7-9), attitude score 76 (70$80)$ and practice score 74 (68-78). Good knowledge predictors were $>20$ years working experience [OR: 2.05 (95\% CI: 1.03-4.06); $\mathrm{P}=0.04$ ] and $>50 \%$ working in clinical practice [OR: 1.72 (95\% CI: 1.12-2.66); $\mathrm{P}=0.01]$, in inverse relationship with paramedical professions [OR: 0.45 (95\% CI: $0.45(0.28-0.72)) ; \mathrm{P}=0.001]$ and working in a university hospital [OR: 0.51 (95\% CI: 0.33. 0.81); $\mathrm{P}=0.004$ ]. Availability of pharmaceutical information and treatment options was associated with good attitude [OR: 2.19 (95\% CI: 1.04-4.59); $\mathrm{P}=0.039$ ] and acquaintance as primary information sources negatively associated with good attitude [OR: 0.34 (95\% CI: $0.15-0.8) ; \mathrm{P}=0.013$ ]. Good practice predictors were female gender [OR: 3.84 (95\% CI: 2.37-6.24); $\mathrm{P}<0.001$ ], military hospital employment [OR: 2.32 (95\% CI: 1.25-4.31); $\mathrm{P}=0.008$ ], USA [OR: 3.41 (95\% CI: 1.03-11.22); $\mathrm{P}=0.044$ ] or UK [OR: 8.86 (95\% CI: 1.91-41.07); $\mathrm{P}=0.005]$ qualifications, and information on supportive measures [OR: 2.2 (95\% CI: 1.36-3.56); $\mathrm{P}=0.001$ ].

Conclusion: Health workers displayed good knowledge about COVID-19, while profession and working experience predicted adequate knowledge, positive attitude, or practice towards disease management.

Keywords: COVID-19, pandemic, pharmacists, knowledge, attitudes, practices

\section{Introduction}

The coronavirus-induced disease -19 (COVID-19) is a contagious respiratory pandemic, first detected and confirmed in Wuhan, China., ${ }^{1,2}$ According to the World Health Organization (WHO), the disease is caused by a severe acute respiratory syndrome coronavirus 2 (SARS-CoV-2). ${ }^{3}$ This virus is a homolog of the coronavirus $(\mathrm{CoV})$ that triggered an outbreak of the severe acute respiratory syndrome (SARS) in $2003 .^{4}$ The disease is known to spread very rapidly and to
Correspondence: Maha M AIRasheed

Tel +966 II 4678707

Fax +966-II-4677480

Email mahalrasheed@ksu.edu.sa 
be passed on through human-to-human; ${ }^{5-7}$ however, there is yet no clear evidence on the origin of the virus. Besides, the transmission route of the SARS-CoV-2 also remains unclear, although some studies have suggested a potential risk for airborne transmission. ${ }^{7,8}$ The most common symptoms are fever and cough, while gastrointestinal symptoms such as diarrhea and vomiting are less frequent. ${ }^{9}$

With the rapid, sharp increase in the reported cases worldwide, the WHO declared the outbreak a global pandemic requiring all countries to make concerted efforts together to combat the disease. This call resulted in countries responding by putting in place stringent precautionary and preventative measures, including travel restrictions contributing to the global cause. These measures were indispensable, and positive participation was necessary to facilitate effective combat against the spread of the disease. However, their success would depend on the prior comprehension of the problem by the population. Specifically, a clear understanding of the disease itself, such as the most common symptoms, protection methods against COVID-19 infection, transmission and management of the disease and the measures in place, and the general perception of the public about the gravity of the problem as well as practicing the obligatory guidelines are among the most critical prerequisites for the public to contain the problem successfully. Thereafter, dealing with the consequences of COVID-19 pandemic quarantine which have been linked with an adverse association with mental health conditions. ${ }^{49}$

Poor understanding of the disease among health care workers (HCWs), on the other hand, is likely to lead to undesired therapeutic outcomes. In contrast, awareness of the disease symptoms, mode of transmission, and infection controls and measures are likely to go a long way in curbing the spread of the disease. Yet, much remains desired with the current level of understanding, how the population conceives the problem, and how they practice the authorities' strategies. Being the professionals at the frontline in combating the disease, the level of understanding and notion of the healthcare workers towards the pandemic is of paramount interest. They will always find themselves closest to the problem directly called upon to execute the institutional chain of requirements. Previous studies demonstrated the vital role of pharmacists during the pandemic and the impact of the pandemic on pharmaceutical care. ${ }^{10}$ However, there is a lack of studies comparing the performance of pharmacists to other healthcare professionals.
Several studies have addressed the level of COVID-19related knowledge, attitude, and practice (KAP) among the $\mathrm{HCWs}^{11-21}$ with widely varying outcomes in various regions of the world. Thus, while some have reported adequate knowledge, good attitude, and practice, many others have found the opposite trends. Besides, studies involving different societal groups or populations have also reported diversity in KAP towards COVID-19 ${ }^{22-29}$ and gaps in these traits among various populations. ${ }^{13,15,18,30}$ Besides, some studies also suggest that the response to these traits may depend on gender, age, or profession. ${ }^{12,14,31,32}$ Thereby, some have reported a negative attitude towards disease, while others have demonstrated good practice of the profession, necessitating more in-depth studies to assess the KAP of HCWs on the COVID-19 pandemic. In particular, there is currently stealth of literature specifically assessing the KAP in HCWs toward COVID-19 in Saudi Arabia, mandating, therefore, further insight into the problem. Therefore, this study aims to assess whether these traits can reveal any specific trends that may discern between pharmacists and other healthcare workers, as this would lay the basis for establishing the way forward in enhancing their competency and correcting any potential misconceptions related to their noble function in the containment of this relentlessly spreading pandemic.

\section{Materials and Methods Study Design, Settings, Population}

A cross-sectional study was conducted in Saudi Arabia hospitals during lockdown starting in June 2020. It is a prospective self-reporting survey using online questionnaires involving health care workers who agreed to participate in the study, such as physicians, pharmacists, dentists, nurses, and technicians practicing a medical profession within Saudi Arabia at the time. We excluded HCWs practicing outside Saudi Arabia. We chose a random sample of healthcare institutions in Saudi Arabia and distributed the questionnaire to their healthcare professionals by email or WhatsApp messages. Additionally, the published study survey was promoted on social media such as Twitter and manually in King Khalid University Hospital (KKUH) to reach the target sample size. The required sample size, calculated using the Stata sample size and power calculator ${ }^{33}$ before conducting our study, was estimated to be 395 participants. We decided to distribute the survey to 1000 participants with 
an expected response rate of $50 \%$ and the expected outcomes among the respondents of $20 \%$. The confidence interval was set to $95 \%$ and a marginal error for type 1 of $5 \%$.

The study was conducted according to the guidelines of the Declaration of Helsinki and approved by the IRB Committee at King Saud University Medical City (KSUMC) (protocol code E-20-4845 and approved on 5th of May 2020).

Written informed consent was obtained from all respondents before participation in the study, with a brief explanation of the objectives and benefits of the study, emphasizing the confidentiality and use of personal data for the scientific work only.

In this research, the participation was completely voluntary; no monetary or non-monetary rewards were provided, and participants were free to leave at any time.

\section{Study Questionnaire}

A self-administered questionnaire was created after an extensive search in the literature based on the recently available information from the World Health Organization (WHO), local Centers for Disease Control and Prevention, and Saudi Ministry of Health websites. The designed questionnaire was validated in two steps. First, the initial draft was sent to a group of research experts in the related fields, most of them are pharmacists, to reflect on relativity, simplicity, and the importance of questions. Secondly, a pilot study was conducted on 12 selected subjects from HCWs to give their opinions on simplifying the questionnaire. Amendments from the pilot study were then integrated into the final questionnaire. Reliability test was done by calculating Cronbach's alpha using SPSS v.24. The data of the pilot study were not included in the final analysis. The final questionnaire was then distributed using online survey tools to all available HCWs in selected locations. We sent one reminder to participants to encourage participation and survey distribution.

The questionnaire was divided into six sections. The first two sections included seven items providing information about work status and COVID-19 source of information. The third section contained questions regarding the most common signs and symptoms, protection methods, transmission, and management of COVID-19. We measured respondents' level of knowledge ( $\mathrm{n}=10$ questions), attitude ( $\mathrm{n}=17$ questions), and their practices ( $\mathrm{n}=16$ questions) towards COVID-19 infection. The last section comprised demographic information of the respondents, including age, gender, and nationality. Questionnaires/ datasheets from other authors (Copyrights or acquired permission to use or open access for academic and research purposes).

\section{Assessment of Knowledge, Attitude, and Practice}

The study instrument assessed the knowledge of HCWs by asking questions about nature, etiology, symptoms, risk group, consequences, method of transmission, prevention, and management of COVID-19. Knowledge scores ranged from $0-10$, with the maximum obtainable score of 10 for each participant. Assessment of attitude was carried out through 17 questions. The responses were recorded on a 5-point Likert scale. A score of 5 was given to strongly agree, 4 agree, 3 undecided, 2 disagree, and 1 to strongly disagree. In the last part, we evaluated respondent practice towards COVID-19 using 16 5-point Likert frequency scale items. A score of 5 was given to always, 4 often, 3 sometimes, 2 rare, and 1 to never. We adopted the modified Bloom's criteria to set the cut-off points for good knowledge, attitude, or practice to be a score of $\geq 80 \%$.

\section{Data Collection and Source}

A team of three researchers established an excel sheet with required fields and weekly data entry. After four months, the data were statistically analyzed from the respondent questionnaires.

\section{Statistical Analysis \\ Data Presentation}

We described categorical data as numbers and percentages and continuous data as median (25th- 75th percentiles). Categorical data were compared with the Chi-squared test or Fisher exact test if the expected frequency was less than 5. Wilcoxon test was used to compare continuous data. Spearman correlation was used to test the relations between knowledge, attitude, and practice scores. A P-value of less than 0.05 was considered statistically significant. All statistical analyses were performed using Stata 16.1 (Stata Corp, College Station, TX, USA).

\section{Multivariable Analysis}

Logistic regression was used to identify the independent predictors for good knowledge, attitude, and practice. Univariable analysis was performed, and variables with a p-value of $<0.2$ were included in a stepwise logistic 
regression model with a forward selection of those with a $p$-value of $<0.1$. We included the socio-demographic variables in the multivariable regression analysis in Table 1.

\section{Results}

\section{Socio-Demographic Data}

There were no differences between the groups regarding gender and age. However, the two groups differed significantly in the distributions of nationality, highest educational level, and work-related variables. The socio-demographic data are presented in Table 1.

\section{Knowledge Assessment}

We assessed the knowledge level in several controversial areas (most common symptoms, protection methods against COVID-19 infection, transmission, and disease management) at the survey time. The responses were reported in Supplementary Table 1. These were not included in the knowledge score calculation. The median knowledge score was 8 (25th- 75th percentiles: 7-9), pointing to no difference in the knowledge score between pharmacists and other healthcare workers $(\mathrm{P}=0.61)$ (Figure 1). There was no difference in the groups' responses to individual questionnaire items (Supplementary Table 2). The cut-off value showing good knowledge was a score of $\geq 8$, with good knowledge being reported in 256 (59.8\%) participants. Good knowledge was inversely related to the paramedical professions (OR: $0.45 ; \mathrm{P}=0.001$ ), whereby working at a university hospital (OR: $0.51 ; \mathrm{P}=0.004$ ), working experience more of than 20 years (OR: 2.05; $\mathrm{P}=0.04$ ), and working over $50 \%$ in clinical practice (OR: $1.72(1.12-2.66) ; \mathrm{P}=0.01$ ) were independent predictors of good knowledge (Table 2).

\section{Attitude Assessment}

The median attitude score was 76 (70-80), showing no difference in the attitude score between groups. The response to each question on the attitude questionnaire was presented in Supplementary Table 3. Among our participants, 376 (87.85\%) had a good attitude. Providing pharmaceutical information and treatment options by the institution was positively related to the good attitude (OR: 2.19 (1.04-4.59); $\mathrm{P}=0.039$ ) and considering neighbors and friends as the primary source of information was negatively associated with a good attitude (OR: 0.34 (0.15$0.8) ; \mathrm{P}=0.013$ ). (Table 3)

\section{Practice Assessment}

The median practice score was 74 (68-78), with no difference between groups. Among the participants, 300 $(70.09 \%)$ had a good practice (practice score $\geq 70$ ). Predictors of good practice were female gender (OR: 3.84 (2.37-6.24); $\mathrm{P}<0.001$ ), non-Saudi nationality (OR: 2.28 (1.27-4.11), $\mathrm{P}=0.006)$, working in a military hospital (OR: 2.32 (1.25-4.31); $\mathrm{P}=0.008)$, getting the highest degree from the USA (OR: 3.41 (1.03-11.22); $\mathrm{P}=0.044)$, or the UK (OR: 8.86 (1.91-41.07); $\mathrm{P}=0.005)$ using newspapers as the primary source of information (OR: 2.9 (1.18-7.12); $\mathrm{P}=0.021)$ and providing information related to the supportive measures by the institution (OR: 2.2 (1.36-3.56); $\mathrm{P}=0.001$ ). (Table 4). The response to each question on the good practice questionnaire was presented in Supplementary Table 4.

\section{Correlations Between Scores}

There was a positive correlation between knowledge and attitude score (Spearman's rho: $-0.28 ; \mathrm{P}<0.001$ ). (Figure 2) However, the correlation between knowledge and practice was non-significant (Spearman's rho: 0.09; $\mathrm{P}=0.07$ ), whereas attitude and practice scores were positively correlated (Spearman's rho: 0.35; $\mathrm{P}<0.001$ ) (Figure 3).

\section{Discussion}

The present study evaluated the KAP of healthcare workers in Saudi Arabia. Our study revealed a good knowledge level toward COVID-19 among the studied cohort in general. However, there were no significant differences between pharmacists and other healthcare professionals. To our knowledge, there is a notable paucity of studies focusing on pharmacists actively engaged in fighting the pandemic in the literature. However, a study in Nepal seems to suggest differences among professions involved in frontline health workers in the pandemic-related KAP variables. ${ }^{18}$ On the other hand, the fact that the study cohort displayed good knowledge and positive attitude towards the disease and appropriate practice of the set guidelines reflects the general applicability of these KAP results to the status of HCWs in general concerning the various aspects of COVID-19 management.

However, many studies have evaluated the KAP traits in HCWs rather than focusing on active participation yielding diverse outcomes. Our findings of positive KAP qualities among $\mathrm{HCWs}$ as a whole concurs with, for example, the study of Qadah, which reported sufficient 
Table I Socio-Demographics Characteristics of the Participants

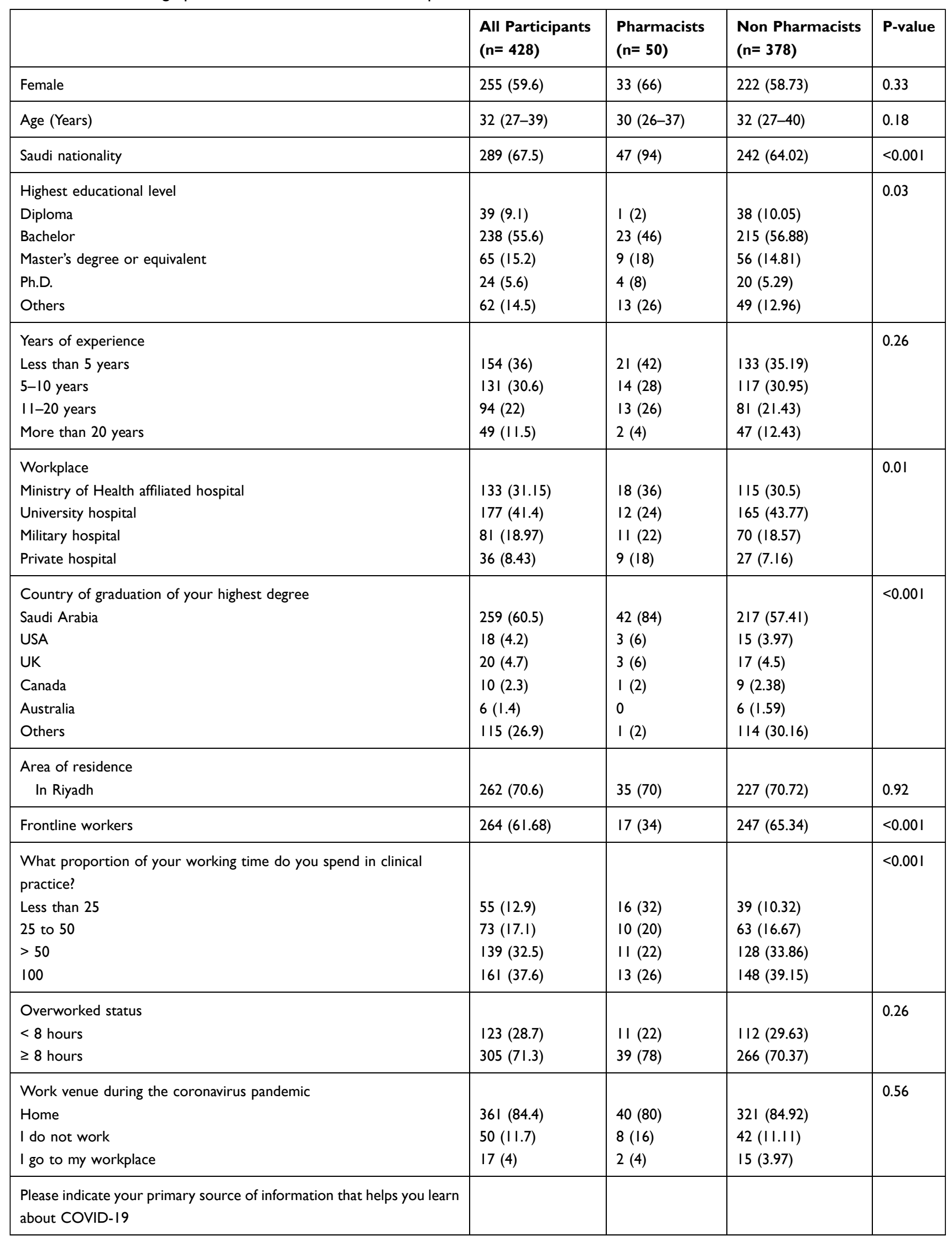

(Continued) 
Table I (Continued).

\begin{tabular}{|c|c|c|c|c|}
\hline & $\begin{array}{l}\text { All Participants } \\
(n=428)\end{array}$ & $\begin{array}{l}\text { Pharmacists } \\
(n=50)\end{array}$ & $\begin{array}{l}\text { Non Pharmacists } \\
(n=378)\end{array}$ & P-value \\
\hline Radio & $23(5.4)$ & $\mathrm{I}(2)$ & $22(5.82)$ & 0.50 \\
\hline TV & $137(32)$ & II (22) & $126(33.33)$ & 0.11 \\
\hline Posters/pamphlets & $103(24.1)$ & $14(28)$ & $89(23.54)$ & 0.49 \\
\hline Peers & $82(19.2)$ & $5(10)$ & $77(20.37)$ & 0.09 \\
\hline Internet & $276(64.5)$ & $33(66)$ & $243(64.29)$ & 0.81 \\
\hline WHO, CDC, MOH websites & $340(79.4)$ & $41(82)$ & $29979.1)$ & 0.63 \\
\hline Social media & $273(63.8)$ & $25(50)$ & $248(65.61)$ & 0.03 \\
\hline Scientific articles & $207(48.4)$ & $31(62)$ & $176(46.56)$ & 0.04 \\
\hline Newspapers & $50(11.7)$ & $4(8)$ & $46(12.17)$ & 0.49 \\
\hline Seminars & $140(32.7)$ & $13(26)$ & $127(33.6)$ & 0.28 \\
\hline Neighbors and friends & $54(12.6)$ & $2(4)$ & $52(13.76)$ & 0.07 \\
\hline Health educator & $209(48.8)$ & $19(38)$ & $190(50.26)$ & 0.10 \\
\hline \multicolumn{5}{|l|}{$\begin{array}{l}\text { Does your institute provide the following continuing education about } \\
\text { COVID-19? }\end{array}$} \\
\hline Facts about the coronavirus COVID-19 & $344(80.4)$ & $36(72)$ & $308(81.48)$ & 0.11 \\
\hline Basic facts about the disease and how it spreads & $350(81.8)$ & $40(80)$ & $310(82.01)$ & 0.73 \\
\hline On-pharmaceutical interventions against COVID-19 & $15 \mid(35.3)$ & $17(34)$ & $134(35.45)$ & 0.84 \\
\hline Pharmaceutical information and available treatment options & $185(43.2)$ & $31(62)$ & $154(40.74)$ & 0.004 \\
\hline Information related to disease prevention and preventative measures & $320(74.8)$ & $27(54)$ & $293(77.5 \mathrm{I})$ & $<0.001$ \\
\hline $\begin{array}{l}\text { Education related to other supportive measures (eg, psychological } \\
\text { support) during this pandemic }\end{array}$ & $256(59.8)$ & $26(52)$ & $230(60.85)$ & 0.23 \\
\hline No continuing education is provided about COVID-19 by my institute & $63(14.7)$ & $7(14)$ & $56(\mid 4.8 I)$ & 0.88 \\
\hline
\end{tabular}

Notes: Continuous variables were presented as median (25th-75th percentiles) and categorical variables as numbers and percentages (given in brackets)

knowledge and positive attitude towards COVID-19 in HCWs in Saudi Arabia ${ }^{20}$ and Olum et al demonstrating sufficient knowledge, positive attitude and good practices toward the disease among HCWs in Uganda. ${ }^{14}$ In contrast, HCWs in Nepal displayed deficiencies in knowledge but practice compounded by both positive and negative viewpoints in combating disease transmission. ${ }^{13}$ While sufficient knowledge but low positive attitude were reported by Parajuli et $\mathrm{al}^{15}$ and good knowledge, albeit with gaps, was identified on specific aspects and practice of the disease containment in the study of Tamang and colleagues. ${ }^{18}$ Bhagavathula et al described poor knowledge of the disease transmission and symptom onset on the one hand, but a positive perception of the pandemic on the other in HCWs. ${ }^{12}$ In Pakistan, despite good knowledge, gaps in specific aspects of knowledge and practice were similarly identified among $\mathrm{HCWs},{ }^{17}$ while in China, the HCWs displayed sufficient knowledge and followed correct practices regarding COVID-19. ${ }^{19}$ In India, researchers observed a moderate level of knowledge about the COVID-19 infection but adequate knowledge about its preventive aspects among HCWs. ${ }^{16}$ The management of
COVID-19-positive cases is difficult because of the administration of medications that may interact with each other, thus, pharmacists reduced prescription issues significantly. ${ }^{34}$

Rather than distinguishing between active involvement and lack thereof among HCWs, our study pointed to some demographic and socio-economic characteristics as more predictive of KAP traits. Thus, a good attitude was attributable to the information provided by the institution during the COVID-19 pandemic. Besides, the good practice exhibited by the participants was linked to gender, military hospitals, and the country where the highest degree was obtained. Interestingly, in our study, good knowledge exhibited an inverse relationship with the paramedical professions. Working in a university hospital and long working experience in clinical practice were independent predictors of the trait. Indeed, apart from healthcare personnel, studies have also been conducted on the KAP of certain other social groups, such as allied health professionals, dentists, medical students, for example, yielding equally varying results. ${ }^{11,21,32,35-38}$ In a study by Abdel Wahed in Egypt, a positive attitude was detected more 


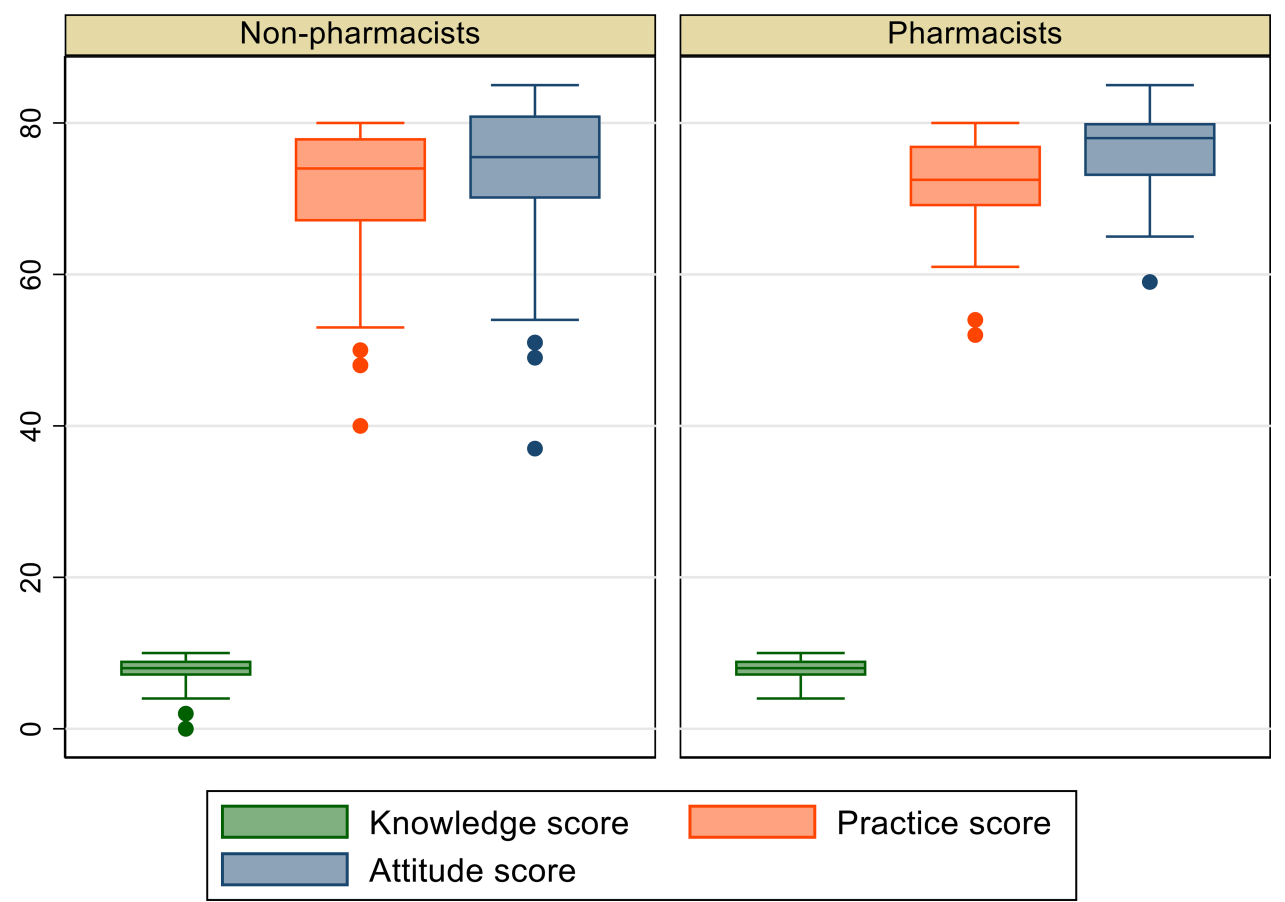

Figure I Box plots of the distribution of knowledge, attitude, and practice scores between pharmacists and other healthcare workers.

among allied health professionals than physicians, while risk perception was high among HCWs in general. ${ }^{11}$ Good knowledgeability has also been found in dentists in Jordan and Mauritius ${ }^{21,35,36}$ and medical students in Jordan, Iran, and China. ${ }^{32,37,38}$ However, while the Jordanian dentists were conscious of COVID-19 symptoms, mode of transmission, and infection controls and measures in dental clinics, ${ }^{35}$ their comprehension of the extra precautionary measures required to protect the staff and patients from contracting the disease was limited. ${ }^{35}$ Also, medical students in Iran displayed a high level of COVID-19- related knowledge, self-reported preventive behaviors, and moderate risk perception. ${ }^{38}$ However, in the study of Peng in China, while most undergraduates acquired the necessary knowledge, positive attitude, and proactive practice in response to the pandemic outbreak, their KAP scores varied significantly by gender, medical major, and school types. $^{32}$
In the general population, respondents have exhibited overall good knowledge regarding the covid-19 pandemic in countries including Saudi Arabia, ${ }^{20,22,23,48}$ Egypt, $^{24}$ India, ${ }^{25}$ China, ${ }^{26}$ Malaysia, ${ }^{27}$ Uganda, ${ }^{28}$ and the USA. ${ }^{29}$ However, while in the majority of these countries, satisfactory knowledge was partly linked to the positive attitude and sensible practices, ${ }^{28}$ in some countries, these trends were observed together with poor practice ${ }^{24}$ or exhibited gaps in knowledge among certain groups such as drivers, business entrepreneurs, and security personnel. ${ }^{28}$ A study from three countries in the Middle East found good knowledge toward disease prevention and control and a lower knowledge score toward disease transmission. ${ }^{39}$ Postgraduate education may help to create best practices for maximizing pharmacists' effectiveness in future emergencies. ${ }^{40}$

In Saudi Arabia, Alahdal et al suggested that despite moderate public awareness, the general population's

Table 2 Multivariable Predictors of Good Knowledge

\begin{tabular}{|l|l|l|}
\hline Good Knowledge & Odds Ratio (95\% Confidence Interval) & P-value \\
\hline Paramedical profession & $0.45(0.28-0.72)$ & 0.001 \\
Working in university Hospital & $0.51(0.33-0.8 I)$ & 0.004 \\
$>50$ work in clinical practice & $1.72(1.12-2.66)$ & 0.014 \\
$>20$ years' experience & $2.05(1.03-4.06)$ & $0.04 I$ \\
\hline
\end{tabular}


Table 3 Multivariable Predictors of Good Attitude

\begin{tabular}{|c|c|c|}
\hline Good Attitude & $\begin{array}{l}\text { Odds Ratio (95\% Confidence } \\
\text { Interval) }\end{array}$ & P-value \\
\hline $\begin{array}{l}\text { The institution provides information about: Pharmaceutical information and available } \\
\text { treatment options }\end{array}$ & $2.19(1.04-4.59)$ & 0.039 \\
\hline Education related to supportive measures (eg, psychological support) & $1.90(0.99-3.64)$ & 0.051 \\
\hline \multicolumn{3}{|l|}{ The primary source of information } \\
\hline Newspapers & $4.08(0.87-19.02)$ & 0.074 \\
\hline Scientific articles & $1.72(0.92-3.22)$ & 0.089 \\
\hline Neighbors and friends & $0.34(0.15-0.8)$ & 0.013 \\
\hline
\end{tabular}

attitude and practice turned out to be better. ${ }^{22}$ However, in the study of Siddiqui et al, the general population exhibited a weak relationship between knowledge and practice, which was followed differently in the five regions of Saudi Arabia. The respondents' levels of education influenced their choice of practice to protect themselves from the effects of COVID-19. ${ }^{41}$ Baig and colleagues found that KAP is related to the level of education and age, which is similar to our findings among HCWs. ${ }^{42}$ The general public in the USA revealed a satisfactory knowledge of the disease and attitude towards instituted preventive measures. However, although most respondents practiced selfisolation and social distancing, only a few followed all health recommendations. ${ }^{29}$ In China, while residents in Hunan Province exhibited good KAP toward COVID$19,{ }^{43}$ inadequate or limited knowledge and lower attitude were prevalent in other studies in which the former was linked with a lower likelihood of negative attitude and preventative practices towards the disease. ${ }^{26}$
Societal or demographic factors appear to influence the KAP levels in various modes among different groups of people. In some studies, differences in knowledge levels and perceptions on certain aspects of preventative practice have been attributed to gender, age, education level, profession, family income, or urban area residence. ${ }^{12,14,31,43,44}$ For example, knowledge inadequacy and poor perception among HCWs have been attributed to age and profession in one study. ${ }^{12}$ In contrast, knowledgeability has been attributed to age and news media and good practices to age and holding a diploma in another. ${ }^{14}$ For example, in a study in Saudi Arabia, men presented with inferior KAP compared to females. ${ }^{23}$ In contrast, in our study, a slightly higher awareness level was observed in male participants. At the same time, a somewhat better practice was found among females, suggesting that gender may significantly influence the level of responses to the KAP traits. Besides, in the general Saudi population, a weak relationship between knowledge and practice was

Table 4 Multivariable Predictors of Good Practice

\begin{tabular}{|l|l|l|}
\hline Good Practice & $\begin{array}{l}\text { Odds Ratio (95\% Confidence } \\
\text { Interval) }\end{array}$ & P-value \\
\hline Female & $3.84(2.37-6.24)$ & $<0.00 I$ \\
\hline Non-Saudi nationality & $2.28(1.27-4.11)$ & 0.006 \\
\hline Military Hospitals & $2.32(1.25-4.31)$ & 0.008 \\
\hline $\begin{array}{l}\text { The institution provides education related to supportive measures (eg, psychological } \\
\text { support) during this pandemic }\end{array}$ & $2.2(1.36-3.56)$ & 0.001 \\
\hline $\begin{array}{l}\text { Country of graduation of the highest degree } \\
\text { USA } \\
\text { UK }\end{array}$ & $3.41(1.03-11.22)$ & 0.044 \\
\hline The primary source of information is from Newspapers & $8.86(1.91-41.07)$ & 0.005 \\
\hline
\end{tabular}




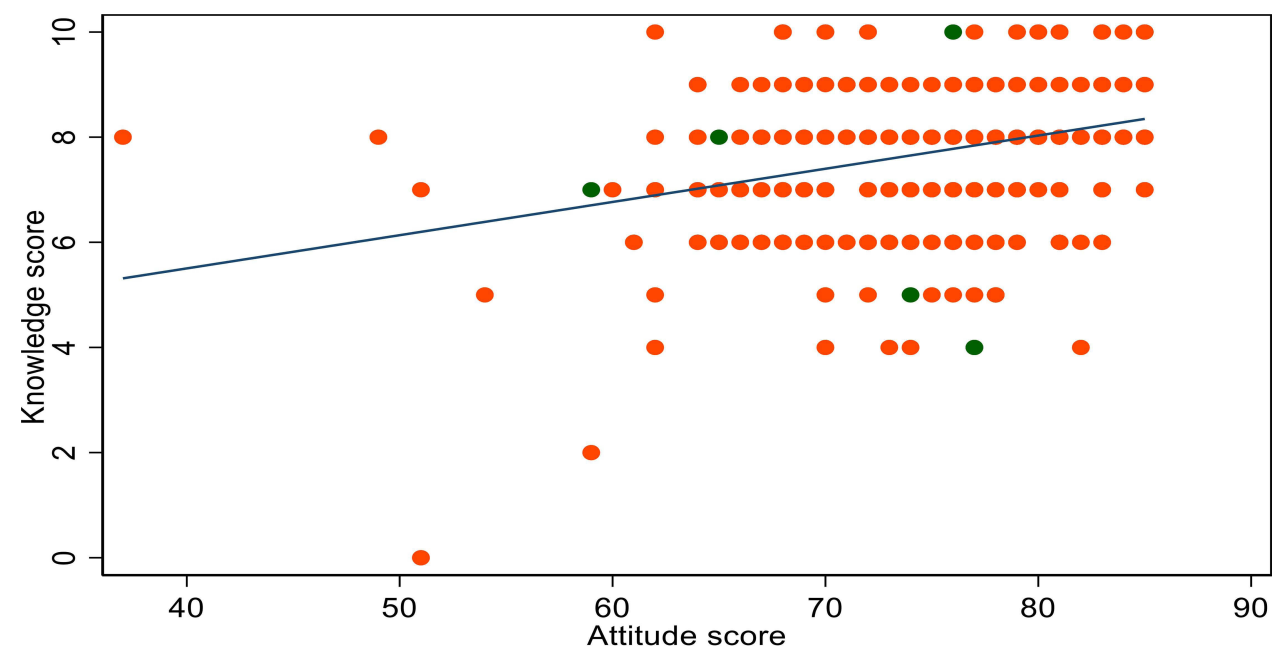

- Pharmacists Non-pharmacists

Figure 2 Scatter plot of knowledge and attitude scores.

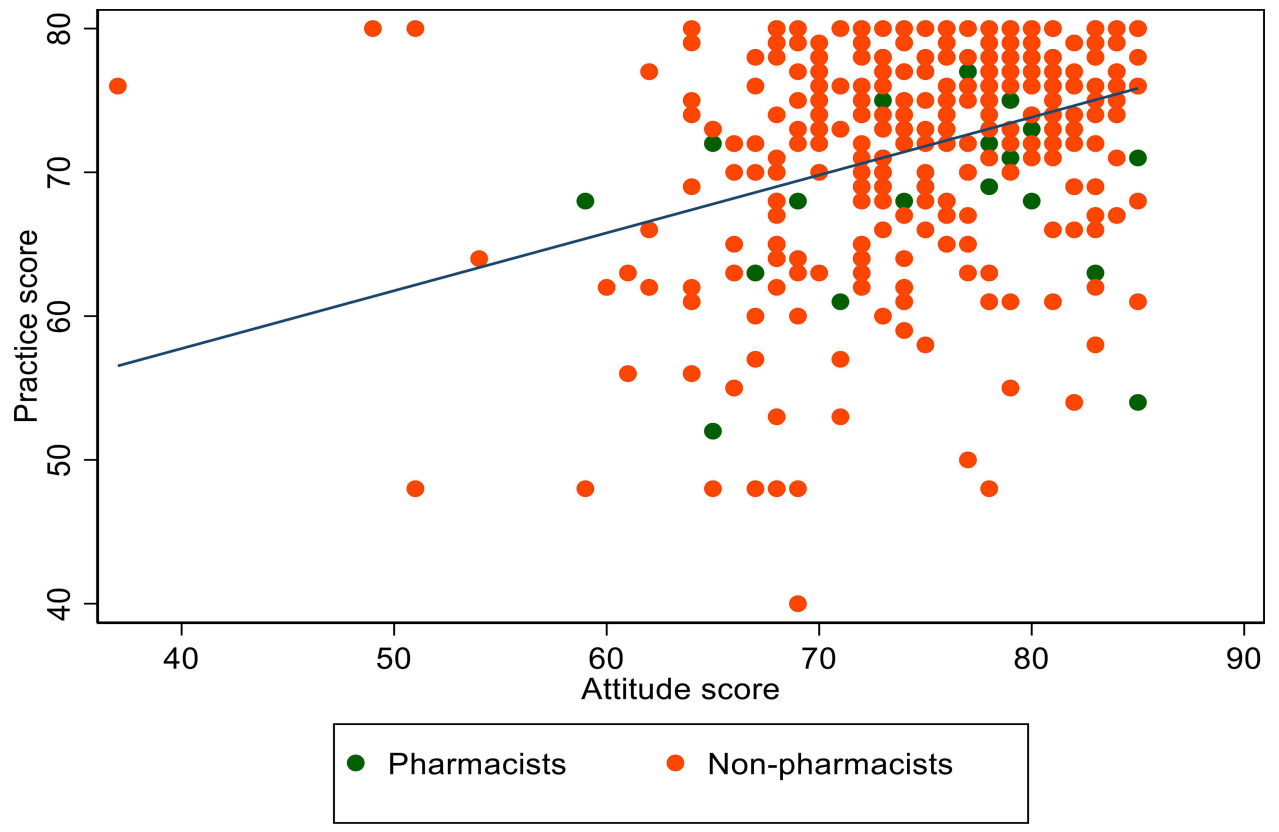

Figure 3 Scatter plot of practice and attitude scores.

attributed to the latter being regionally pursued differently and the choice of practice to protect themselves from the effects of COVID-19 being influenced by their education level. ${ }^{41}$ In China, individuals of relatively high socioeconomic status, especially women, were knowledgeable about COVID-19, holding optimistic attitudes and showing appropriate practices towards the disease among Chinese residents. ${ }^{26}$ Good knowledge and lower practice level were found among middle-aged, working individuals and those with insufficient income in Egypt. ${ }^{24}$ Another study in the same population indicated that knowledge was significantly lower among older, less educated, lowerincome participants and rural residents, with most of them being concerned about the risk of infection. ${ }^{31}$ In the USA, knowledge levels were influenced by respondents' age, education, and background. Besides, racial and socioeconomic disparity and comorbidity conditions appear to contribute to poor levels of KAPs related to COVID- 
$19 .^{45,46}$ In addition to comorbidities and demographic features, some risk factors, including fear of the virus itself, the impact of the disease, anxiety, fear, work experience, and job category, may also affect the KAP of individuals. ${ }^{16,19,21,41,44}$ Thus, Ahmed et al suggested that despite having a high standard of knowledge and practice, dental practitioners could be working in a state of anxiety and fear towards the impact of the COVID-19 pandemic worldwide. $^{21}$ At the same time, in China, respondents displayed fear of self-infection with the virus. ${ }^{19}$ In a study by Roy et al in India, while the attitude towards COVID-19 guidelines on quarantine and social distancing was adequate, anxiety reigned among the respondents. ${ }^{16}$ Thus, apart from the specific professional groups, the general public has also shown variations in KAP traits possibly influenced differently by diverse factors around the world.

Pharmacists may assist relieve the load by offering patient education on chronic illness management and functioning as a medication information resource for patients and healthcare staff. ${ }^{47}$

These variations may be related to the quality of the information on the disease, as this often depends on the source of information. Thus, the more accessible a reliable source is, the better the quality and more useful the extractable information would be extracted, especially for a subject such as this one. In Saudi Arabia, for example, the World Health Organization (WHO) and the Ministry of Health $(\mathrm{MOH}),{ }^{22}$ social media, and the workplace were employed as their source of information in some studies. ${ }^{20}$ In the current study, however, the primary sources of information were health educators and newspapers, which may be limited concerning the nature of the dissipated relevant information. Other studies blamed the lack of information for the observed low KAPs in their studies. Hence, the differences in the availability of quality information may answer the variations observed in the KAP levels among different social groups or populations. Put together, therefore, there is no common denominator for the quality of KAP responses among the various groups or populations of the world, as they appear to depend on prevailing environmental factors, demographic characteristics, and to be influenced by the quality of accessible information in the respective groups.

Strengths and limitations

The current research has some drawbacks, such as using a cross-sectional design and a convenience sample method, which could restrict our ability to generalize our findings to other pharmacists and healthcare providers worldwide. Moreover, the study relied on self-reported responses of the HCWs. However, since no previous research has conducted a similar study, this is the first comparative cross-sectional study to examine pharmacists' and other healthcare workers' knowledge, attitude, and practice about COVID-19. The presence of a scoring system allows the analysis to be evaluated with confidence.

\section{Conclusion}

In conclusion, this study showed that healthcare workers displayed good KAP levels towards COVID-19-related issues. Profession and working experience predicted adequate knowledge, positive attitude, or appropriate practice towards disease management. However, the KAP response' levels indicate that efforts should be directed to enhance the contribution of the HCWs in the fight to contain the disease. The observation that certain traits were better predictors for good knowledge and practice necessitates educating the health workers at different levels.

\section{Data Sharing Statement}

Data will be made available on request.

\section{Ethical Consideration}

The study was conducted according to the guidelines of the Declaration of Helsinki and approved by the IRB Committee at King Saud University Medical City (KSUMC) (protocol code E-20-4845 and date of approval 05 May 2020).

\section{Acknowledgment}

This research project was supported by a grant from the "Research Center of the Female Scientific and Medical Colleges", Deanship of Scientific Research, King Saud University.

\section{Author Contributions}

All authors made a significant contribution to the work reported, whether that is in the conception, study design, execution, acquisition of data, analysis, and interpretation, or in all these areas; took part in drafting, revising, or critically reviewing the article; gave final approval of the version to be published; have agreed on the journal to which the article has been submitted, and agree to be accountable for all aspects of the work. 


\section{Funding}

This research received no external funding.

\section{Disclosure}

The authors report no conflicts of interest in this work.

\section{References}

1. Chakraborty C, Sharma AR, Sharma G, Bhattacharya M, Lee SS. SARS-CoV-2 causing pneumonia-associated respiratory disorder (COVID-19): diagnostic and proposed therapeutic options. Eur Rev Med Pharmacol Sci. 2020;24(7):4016-4026. doi:10.26355/ eurrev 20200420871

2. Contini C, Di Nuzzo M, Barp N, et al. The novel zoonotic COVID-19 pandemic: an expected global health concern. J Infect Dev Ctries. 2020;14(3):254-264. doi:10.3855/jidc.12671

3. Adhikari SP, Meng S, Wu YJ, et al. Epidemiology, causes, clinical manifestation and diagnosis, prevention and control of coronavirus disease (COVID-19) during the early outbreak period: a scoping review. Infect Dis Poverty. 2020;9(1):29. doi:10.1186/s40249-02000646-x

4. Yi Y, Lagniton PNP, Ye S, Li E, Xu RH. COVID-19: what has been learned and to be learned about the novel coronavirus disease Int J Biol Sci. 2020;16(10):1753-1766. doi:10.7150/ijbs.45134

5. Guo YR, Cao QD, Hong ZS, et al. The origin, transmission and clinical therapies on coronavirus disease 2019 (COVID-19) outbreak - an update on the status. Mil Med Res. 2020;7(1):11. doi:10.1186/ s40779-020-00240-0

6. Rothan HA, Byrareddy SN. The epidemiology and pathogenesis of coronavirus disease (COVID-19) outbreak. J Autoimmun. 2020;109:102433. doi:10.1016/j.jaut.2020.102433

7. Wiersinga WJ, Rhodes A, Cheng AC, Peacock SJ, Prescott HC. Pathophysiology, transmission, diagnosis, and treatment of coronavirus disease 2019 (COVID-19): a Review. JAMA. 2020;324 (8):782-793. doi:10.1001/jama.2020.12839

8. Morawska L, Tang JW, Bahnfleth W, et al. How can airborne transmission of COVID-19 indoors be minimised? Environ Int 2020;142:105832. doi:10.1016/j.envint.2020.105832

9. Guan WJ, Ni ZY, Hu Y, et al. Clinical characteristics of coronavirus disease 2019 in China. $N$ Engl $J$ Med. 2020;382(18):1708-1720. doi:10.1056/NEJMoa2002032

10. Koster ES, Philbert D, Bouvy ML. Impact of the COVID-19 epidemic on the provision of pharmaceutical care in community pharmacies. Res Social Adm Pharm. 2021;17(1):2002-2004. doi:10.1016/j.sapharm.2020.07.001

11. Abdel Wahed WY, Hefzy EM, Ahmed MI, Hamed NS. Assessment of Knowledge, attitudes, and perception of health care workers regarding COVID-19, A cross-sectional study from Egypt. J Community Health. 2020;45(6):1242-1251. doi:10.1007/s10900020-00882-0

12. Bhagavathula AS, Aldhaleei WA, Rahmani J, Mahabadi MA, Bandari DK. Knowledge and perceptions of COVID-19 among health care workers: cross-sectional Study. JMIR Public Health Surveill. 2020;6(2):e19160. doi:10.2196/19160

13. Ghimire P, Dhungel S, Pokhrel A. Knowledge, attitude and practice of healthcare workers towards coronavirus disease 2019 (COVID-19) pandemic. J Nepal Health Res Counc. 2020;18(2):293-300. doi:10.33314/jnhrc.v18i2.2658

14. Olum R, Chekwech G, Wekha G, Nassozi DR, Bongomin F. Coronavirus disease-2019: knowledge, attitude, and practices of health care workers at makerere university teaching hospitals, Uganda. Front Public Health. 2020;8:181. doi:10.3389/ fpubh.2020.00181
15. Parajuli J, Mishra P, Sharma S, et al. Knowledge and attitude about COVID 19 among health care workers working in Seti Provincial Hospital. J Nepal Health Res Counc. 2020;18(3):466-471. doi:10.33314/jnhrc.v18i3.2816

16. Roy D, Tripathy S, Kar SK, Sharma N, Verma SK, Kaushal V. Study of knowledge, attitude, anxiety \& perceived mental healthcare need in Indian population during COVID-19 pandemic. Asian J Psychiatr. 2020;51:102083. doi:10.1016/j.ajp.2020.102083

17. Saqlain M, Munir MM, Rehman SU, et al. Knowledge, attitude, practice and perceived barriers among healthcare workers regarding COVID-19: a cross-sectional survey from Pakistan. J Hosp Infect. 2020;105(3):419-423. doi:10.1016/j.jhin.2020.05.007

18. Tamang N, Rai P, Dhungana S, et al. COVID-19: a National Survey on perceived level of knowledge, attitude and practice among frontline healthcare Workers in Nepal. BMC Public Health. 2020;20 (1):1905. doi:10.1186/s12889-020-10025-8

19. Zhang M, Zhou M, Tang F, et al. Knowledge, attitude, and practice regarding COVID-19 among healthcare workers in Henan, China. J Hosp Infect. 2020;105(2):183-187. doi:10.1016/j.jhin.2020.04.012

20. Qadah T. Knowledge and attitude among healthcare workers towards COVID-19: a cross sectional study from Jeddah city, Saudi Arabia. J Infect Dev Ctries. 2020;14(10):1090-1097. doi:10.3855/jidc.13083

21. Ahmed MA, Jouhar R, Ahmed N, et al. Fear and practice modifications among dentists to combat novel coronavirus disease (COVID-19) outbreak. Int J Environ Res Public Health. 2020;17 (8):2821. doi:10.3390/ijerph17082821

22. Alahdal H, Basingab F, Alotaibi R. An analytical study on the awareness, attitude and practice during the COVID-19 pandemic in Riyadh, Saudi Arabia. J Infect Public Health. 2020;13 (10):1446-1452. doi:10.1016/j.jiph.2020.06.015

23. Al-Hanawi MK, Angawi K, Alshareef N, et al. Knowledge, attitude and practice toward COVID-19 among the public in the Kingdom of Saudi Arabia: a cross-sectional Study. Front Public Health. 2020;8:217. doi:10.3389/fpubh.2020.00217

24. Kasemy ZA, Bahbah WA, Zewain SK, et al. Knowledge, attitude and practice toward COVID-19 among Egyptians. J Epidemiol Glob Health. 2020;10(4):378-385. doi:10.2991/jegh.k.200909.001

25. Dkhar SA, Quansar R, Saleem SM, Khan SMS. Knowledge, attitude, and practices related to COVID-19 pandemic among social media users in J\&K, India. Indian J Public Health. 2020;64(6):S205-s210. doi:10.4103/ijph.IJPH_469_20

26. Zhong BL, Luo W, Li HM, et al. Knowledge, attitudes, and practices towards COVID-19 among Chinese residents during the rapid rise period of the COVID-19 outbreak: a quick online cross-sectional survey. Int J Biol Sci. 2020;16(10):1745-1752. doi:10.7150/ijbs.45221

27. Azlan AA, Hamzah MR, Sern TJ, Ayub SH, Mohamad E. Public knowledge, attitudes and practices towards COVID-19: a cross-sectional study in Malaysia. PLoS One. 2020;15(5):e0233668. doi:10.1371/journal.pone. 0233668

28. Ssebuufu R, Sikakulya FK, Mambo SB, et al. Knowledge, attitude, and self-reported practice toward measures for prevention of the spread of COVID-19 Among Ugandans: a nationwide online cross-sectional survey. Front Public Health. 2020;8:618731. doi:10.3389/fpubh.2020.618731

29. Geldsetzer P. Knowledge and perceptions of COVID-19 among the general public in the United States and the United Kingdom: a cross-sectional online survey. Ann Intern Med. 2020;173 (2):157-160. doi:10.7326/m20-0912

30. Alyami MH, Naser AY, Orabi MAA, Alwafi H, Alyami HS. Epidemiology of COVID-19 in the Kingdom of Saudi Arabia: an ecological study. Front Public Health. 2020;8:506. doi:10.3389/ fpubh.2020.00506

31. Abdelhafiz AS, Mohammed Z, Ibrahim ME, et al. Knowledge, perceptions, and attitude of egyptians towards the novel coronavirus disease (COVID-19). J Community Health. 2020;45(5):881-890. doi:10.1007/s10900-020-00827-7 
32. Peng Y, Pei C, Zheng Y, et al. A cross-sectional survey of knowledge, attitude and practice associated with COVID-19 among undergraduate students in China. BMC Public Health. 2020;20(1):1292. doi:10.1186/s12889-020-09392-z

33. Raosoft Sample size calculator. Raosoft; 2004. Available from http:// www.raosoft.com/samplesize.html. Accessed June 4, 2020.

34. Perez M, Masse M, Deldicque A, et al. Analysis of clinical pharmacist interventions in the COVID-19 units of a French university hospital. Eur J Hosp Pharm. 2021:ejhpharm-2020-002542. doi:10.1136/ejhpharm-2020-002542.

35. Khader Y, Al Nsour M, Al-Batayneh OB, et al. Dentists' awareness, perception, and attitude regarding COVID-19 and infection control: cross-sectional study among Jordanian Dentists. JMIR Public Health Surveill. 2020;6(2):e18798. doi:10.4103/ijph.IJPH_469_20

36. Kamate SK, Sharma S, Thakar S, et al. Assessing knowledge, attitudes and practices of dental practitioners regarding the COVID-19 pandemic: a multinational study. Dent Med Probl. 2020;57(1):11-17. doi:10.17219/dmp/119743

37. Khasawneh AI, Humeidan AA, Alsulaiman JW, et al. Medical Students and COVID-19: knowledge, attitudes, and precautionary measures. a descriptive study from Jordan. Front Public Health. 2020;8:253. doi:10.3389/fpubh.2020.00253

38. Taghrir MH, Borazjani R, Shiraly R. COVID-19 and Iranian medical students; a survey on their related-knowledge, preventive behaviors and risk perception. Arch Iran Med. 2020;23(4):249-254. doi:10.34172/aim.2020.06

39. Naser AY, Dahmash EZ, Alsairafi ZK, et al. Knowledge and practices during the COVID-19 outbreak in the Middle East: a cross-sectional study. Int $J$ Environ Res Public Health. 2021;18(9):4699. doi:10.3390/ijerph18094699

40. Moore WJ, Webb A, Morrisette T, et al. Impact of COVID-19 pandemic on training of pharmacy residents and fellows: results from a national survey of postgraduate pharmacy trainees. $\mathrm{Am}$ J Health Syst Pharm. 2021;78(12):1104-1111. doi:10.1093/ajhp/ zxab114
41. Siddiqui AA, Alshammary F, Amin J, et al. Knowledge and practice regarding prevention of COVID-19 among the Saudi Arabian population. Work. 2020;66(4):767-775. doi:10.3233/wor-203223

42. Baig M, Jameel T, Alzahrani SH, et al. Predictors of misconceptions, knowledge, attitudes, and practices of COVID-19 pandemic among a sample of Saudi population. PLoS One. 2020;15(12):e0243526. doi:10.1371/journal.pone.0243526

43. Li C, Xu J, Yue L, Shen M, Dai M, Liu N. Knowledge, attitude, and practice survey regarding coronavirus disease 2019 among residents in Hunan Province. Zhong Nan Da Xue Xue Bao Yi Xue Ban. 2020;45 (6):665-672. doi:10.11817/j.issn.1672-7347.2020.200277

44. Habib MA, Dayyab FM, Iliyasu G, Habib AG. Knowledge, attitude and practice survey of COVID-19 pandemic in Northern Nigeria. PLoS One. 2021;16(1):e0245176. doi:10.1371/journal.pone.0245176

45. Alobuia WM, Dalva-Baird NP, Forrester JD, Bendavid E, Bhattacharya J, Kebebew E. Racial disparities in knowledge, attitudes and practices related to COVID-19 in the USA. J Public Health. 2020;42(3):470-478. doi:10.1093/pubmed/fdaa069

46. Wolf MS, Serper M, Opsasnick L, et al. Awareness, attitudes, and actions related to COVID-19 among adults with chronic conditions at the onset of the U.S. Outbreak: a Cross-sectional Survey. Ann Intern Med. 2020;173(2):100-109. doi:10.7326/m20-1239

47. Moreau $\mathrm{C}$. The pharmacist as part of the primary care team during the COVID-19 pandemic. J Am Board Fam Med. 2021;34(Suppl): S21-s25. doi:10.3122/jabfm.2021.S1.200180

48. AlRasheed MM, Alsugair AM, Almarzouqi HF, et al. Assessment of knowledge, attitude, and practice of security and safety workers toward the COVID-19 pandemic: a cross-sectional Study. Front Public Health. 2021;9:631717. doi:10.3389/fpubh.2021.631717

49. AlRasheed MM, AlKadir AM, Bin Shuqiran KI, Al-Aqeel S, Jahrami HA, BaHammam AS. The impact of quarantine on sleep quality and psychological distress during the COVID-19 pandemic. Nat Sci Sleep. 2021;Volume 13:1037-1048. doi:10.2147/NSS. S313373
Risk Management and Healthcare Policy

\section{Publish your work in this journal}

Risk Management and Healthcare Policy is an international, peerreviewed, open access journal focusing on all aspects of public health, policy, and preventative measures to promote good health and improve morbidity and mortality in the population. The journal welcomes submitted papers covering original research, basic science, clinical \& epidemiological studies, reviews and evaluations,

\section{Dovepress}

guidelines, expert opinion and commentary, case reports and extended reports. The manuscript management system is completely online and includes a very quick and fair peer-review system, which is all easy to use. Visit http://www.dovepress.com/testimonials.php to read real quotes from published authors. 